\title{
Surgical Emergencies in Obstetrics and Gynaecology in a Tertiary Care Hospital
}

\author{
Hanoon P Pokharel, ' Prerana Dahal, ' Rubina Rai, ${ }^{1}$ Shyam Sundar Budhathoki \\ 'Department of Obstetrics and Gynaecology, BP Koirala Institute of Health Sciences, ${ }^{2}$ School of Public Health and Community \\ Medicine, BP Koirala Institute of Health Sciences, Dharan, Nepal.
}

\section{ABSTRACT}

Introduction: The management of Obstetrics and Gynaecological Emergency is directed at the preservation of life, health, sexual function and the perpetuation of fertility. Main aim of the study was to access the burden of Surgical Emergency in Obstetrics and Gynaecology and their course of management at BPKIHS.

Methods: A total of 314 women presenting at the emergency admission room of Obstetrics and Gynaecology Department of BPKIHS over two years, who required surgical intervention were included in this hospital based descriptive study. Clinical assessment and routine laboratory investigations were performed in all cases. All patients who presented with shock were resuscitated and surgery was done at earliest possible time.

Results: The age of patients ranged from 15- 55 years with approximately $43 \%$ in the $25-34$ years category. Ninety two percent of them were married. Among the unmarried, $64 \%$ came with problems related to unsafe abortion. About $61 \%$ of females presenting as acute surgical abdomen had ruptured ectopic pregnancy, 7.64\% had twisted ovarian cyst, and 6.26\% had haemoperitoneum and pyoperitoneum following vaginal hysterectomies, total abdominal hysterectomies and caesarean section. Almost half $(47.8 \%)$ of the cases underwent salphingectomy.

Conclusions: Women present with wide range of complaints and conditions in the admission room of Obstetrics and Gynecology department of BPKIHS. Skilled clinicians, immediate investigation facilities and experienced specialty Obstetrical and Gynaecological surgeons are the main backbone of the emergency case management and saving lives. Study indicates there is need of some prospective study to establish the causes of rising trend in Ectopic Pregnancies.

Keywords: ectopic pregnancy; emergency; gynaecological; obstetrics.

\section{INTRODUCTION}

The management of women presenting to the emergency department with obstetric or gynecologic complaints is an obvious and expected occurrence in everyday life in emergency. ${ }^{1}$ Most of the patients present with acute abdomen, abnormal vaginal bleeding or a combination of both. The developments of ultrasonographic imaging, serial biochemical pregnancy tests and minimal invasive surgery have given opportunity for early diagnosis and conservative treatment. ${ }^{2}$

Correspondence: Dr. Hanoon P Pokharel, Department of Obstetrics and Gynecology, BP Koirala Institute of Health Sciences, Dharan, Nepal. Email: hanoonparas@gmail.com, Phone: +977-25-525555 Ext. $5370,+977-9842456085$. 
Gynecologic disorders presenting with Acute Abdominopelvic Pain (AAP) may be benign and self-limiting or may negatively affect fertility capacity if not treated. The incidence is calculated as $1.5 \%$ of office based visits and $5 \%$ of emergency department admissions. The delay in diagnosis and treatment may lead to worse outcomes. ${ }^{3,4}$ The sufferings of the patients in terms of morbidity, mortality and economy can be reduced to some extent by improving these shortcomings. ${ }^{5}$

This study was carried out with an objective of evaluating the gravity of emergencies and to highlight various obstetrical and gynaecological problems presenting as acute surgical emergencies and their management at a tertiary care teaching hospital in Eastern Nepal.

\section{METHODS}

This is a hospital-based descriptive study, carried out at a tertiary teaching hospital in Sunsari district of east Nepal from April 2010 till March 2012. A total of 314 women were included in the study selected by consecutive method of non-probability sampling technique among the patients who presented to the Obstetrics and Gynaecology emergency room at the hospital during the study period. All cases requiring surgical intervention were included in the study. Cases requiring conservative management were excluded. Immediate resuscitation followed by detailed history taking, physical examinations, lab investigations including ultrasonography for diagnosis and appropriate management were done as per the existing protocol for all patients. Data was collected using semi-structured questionnaire, treatment records and intra-operative findings after taking consent from the patient's closest visitor. This study was conducted after taking ethical clearance from the Institute Ethical Review Board.

\section{RESULTS}

Out of a total of 314 patients in the study, the highest number of patients 134 (42.7\%) was seen in the 25 to 34 years category which was followed by 104 (33.1\%) patients in the $15-24$ years category and $60(19.1 \%)$ of the patients were present in the 35-44 years category (Table 1).

\begin{tabular}{|lll|}
\hline $\begin{array}{l}\text { Table 1. Age, marital status, ethnicity and parity } \\
\text { status of the patients }(\mathbf{n}=314) \text {. }\end{array}$ \\
\hline Characteristics & & Number $(\%)$ * \\
& $15-24$ years & $104(33.1 \%)$ \\
Age category & $25-34$ years & $134(42.7 \%)$ \\
& $35-44$ years & $60(19.1 \%)$ \\
& $\geq 45$ years & $16(5.1 \%)$ \\
Marital Status & Married & $289(92.0 \%)$ \\
& Unmarried & $25(8 \%)$ \\
& Adivasi/Janajati & $110(35 \%)$ \\
Ethnicity & except newar & $78(24.8 \%)$ \\
& Brahmin/Chhettri & $72(22.9 \%)$ \\
& Terai castes & $16(5.1 \%)$ \\
& Newar & $38(12.1 \%)$ \\
Parity & Others & $222(70.7 \%)$ \\
& Multipara & $66(21 \%)$ \\
& Primipara & $26(8.3 \%)$ \\
\hline
\end{tabular}

*Percentages based on multiple responses.

Total $273(87 \%)$ of patients were from 12 districts in Nepal, with 139 (51\%) of total from Sunsari and Jhapa districts. Patients from various states of India also comprised of almost $13 \%$.

The most common presenting complaints was pain in abdomen in $238(75.8 \%)$ of the patients followed by bleeding per vagina among $66(21.0 \%)$ of the patients, hemoperitoneum among $34(10.8 \%)$ of the patients and vomiting among $34(10.8 \%)$ of the patients (Figure 1).

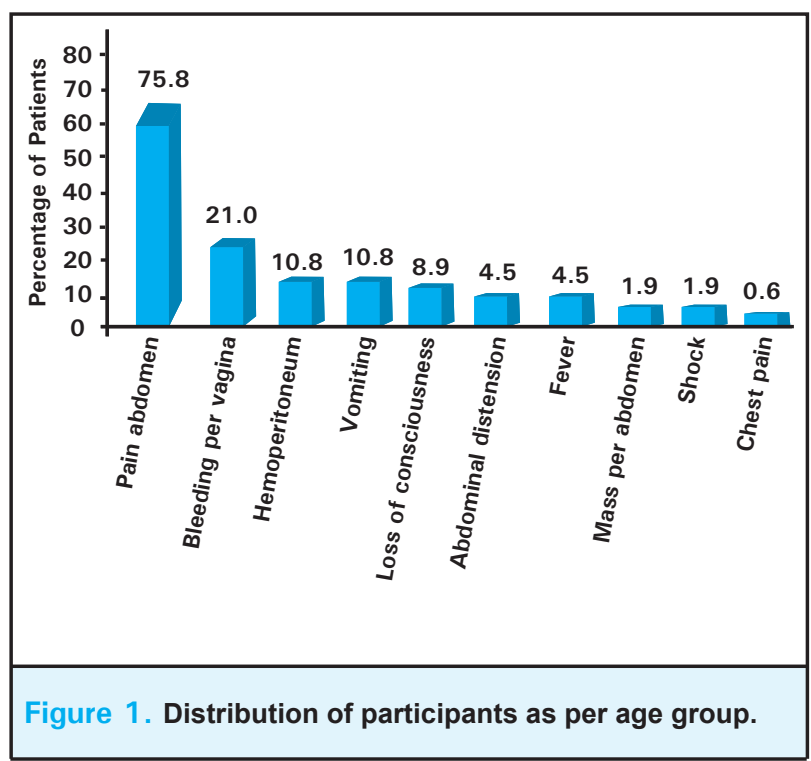

*Percentages based on multiple responses. 
Among the 25 unmarried cases, who presented at the emergency, $16(64 \%)$ of the cases came with problems related to unsafe abortion.

Out of 314 patients a total of $192(61.1 \%)$ of the patients were diagnosed with ectopic pregnancy followed by ovarian mass 24 (7.6\%) (Table 2).

\begin{tabular}{|ll|}
\hline $\begin{array}{l}\text { Table 2. Diagnosis of the patients at the emergency } \\
\text { room. }\end{array}$ \\
\hline Diagnosis & Frequency(\%) \\
Ectopic Pregnancy & $192(61.1 \%)$ \\
Ovarian Mass/Cyst & $24(7.6 \%)$ \\
Twisted/Ruptured Ovarian cyst & $24(7.6 \%)$ \\
Post VH, TAH, LSCS & $20(6.3 \%)$ \\
Ruptured Uterus & $18(5.7 \%)$ \\
PPH & $10(3.2 \%)$ \\
Ovarian cyst with pregnancy & $10(3.2 \%)$ \\
Hydatidiform Mole & $2(0.6 \%)$ \\
\hline
\end{tabular}

A total of 150 (47.8\%) underwent Salphingectomy and $116(37.0 \%)$ were treated with Sub-total Abdominal Hysterectomy (SAH) or Total Abdominal Hysterectomy with Bilateral Salphingo-oopherectomy (TAH with BSO) (Table 3).

\begin{tabular}{|ll|}
\hline $\begin{array}{l}\text { Table 3. Emergency procedures/operations performed } \\
\text { on the patients. }\end{array}$ \\
\hline Procedures/Operations & Number (\%) \\
Salphingectomy & $150(47.7 \%)$ \\
SAH/ TAH+BSO & $116(36.9 \%)$ \\
Salphingectomy with Tubal ligation & $34(10.8 \%)$ \\
Repair of ruptured uterus & $14(4.5 \%)$ \\
\hline
\end{tabular}

\section{DISCUSSION}

A wide variety of cases with surgical emergencies in obstetrics and gynecology are encountered in emergency room starting from young girls to older women at hospitals worldwide. A total of 192 cases of ruptured ectopic pregnancies were seen in this study. $A$ study done for similar duration showed a total of 143 cases of ruptured ectopic pregnancy at BPKIHS. ${ }^{6}$ The number of ectopic pregnancy in this study is higher in comparison with 174 cases seen in five years in a study done at Tribhuwan University Teaching Hospital (TUTH). Other studies in Nepal showed a total of 36 cases of ectopic pregnancy was seen in five years in a study at Nepal Medical College Teaching Hospital, a total of 167 cases in five years by another study at TUTH, and 88 cases in two years in a study at BandB Hospital Kathmandu. ${ }^{7-10}$ The reason for greater number of cases at BPKIHS is that it is the only Teaching Hospital in the eastern region with residency program in Obstetrics and Gynecology and is considered as a Regional Hospital with a tertiary care services serving a large number of population from both Nepal and India. This slight increase in number in BPKIHS from the study in 2004 to the current study may be due to increasing number of cases at emergency room of BPKIHS in the present years. $^{6}$

The most common gynecological and obstetrical emergency encountered in this study was ectopic pregnancy, which is comparable with the findings in a teaching hospital in Nigeria, where ectopic pregnancy was the commonest indication for surgery. ${ }^{11}$ Another study in Nairobi, Kenya also showed that ectopic pregnancy was the most common cause for emergency laparotomy among women. ${ }^{12} \mathrm{~A}$ study however showed that, Pelvic Inflammatory Disease was the most common gynecological emergency in their district hospital at Kasur, Pakistan. ${ }^{5}$

The age group of patients in our study ranged from 15 to 55 years, similar to the study in Kasur, Pakistan, and different from another study in Lahore, Pakistan where all the patients were in the category of 15 to 35 years. ${ }^{5,13}$

Most common presenting complaint was pain in the abdomen $(75.8 \%)$ followed by bleeding per vagina $(21 \%)$ in this study. A study in Turkey also showed that abdomino pelvic pain (59\%) was the most common complaint followed by vaginal bleeding $(41 \%) .^{14}$

About $48 \%$ of the patients underwent only Salphingectomy, which is also the most common surgery done for ectopic pregnancy. Nearly $11 \%$ patients also underwent salphingectomy with contralateral tubal ligation after taking consent for those wishing for permanent sterilization.

Septic abortion with uterine perforation accounted for $7 \%$ of the gynecological emergencies in a study in Nigeria. ${ }^{11}$ There was a similar finding in this study with almost $5 \%$ of unsafe abortion out of the total 314 cases. This number is also worrisome to us abortion in Nepal has been legalized, and safe abortion is widely promoted. There could be some gaps that have led to this percentage of people to still under go unsafe abortion.

\section{CONCLUSIONS}

This study reveals that obstetrical and gynaecological emergencies are common in tertiary care centers like BPKIHS. At the same time it can be observed that some of them could have been avoided with minimal 
precautions, counseling and pre-conceptual care in time. Obstetricians and gynaecologists can do better management of these cases, if peripheral health institutions refer the patients timely once the diagnosis of AAP is confirmed.
Studies referred in this article as well as this current study are an attempt to highlight the gap between the poor awareness of the local health institutions regarding the acute lower abdomen pain and the availability of the services in a better center for the management of the Obstetrical and gynaecological surgical emergencies.

\section{REFERENCES}

1. Coppola M, Della-Giustina DA. Obstetric and gynecologic emergencies. Emerg Med Clin N Am. 2003;21:xi-xii.(accessed 12 April, 2012)

2. Ramphal SR, Moodley J. Emergency gynaecology. Best Pract Res Clin Obstet Gynaecol. 2006;20:729-50.

3. Kamin RA, Nowicki TA, Courtney DS, Powers RD. Pearls and pitfalls in the emergency department evaluation of abdominal pain. Emerg Med Clin North Am. 2003;21:61-72.

4. Jermy K, Bourne T. The role of ultrasound in the management of the acute gynaecological abdomen. Rev Gynaecol Pract. 2004;4:224-9.

5. All S, Shah STA. Gynaecological Emergencies. Professional Med J. 2007;14(1):43-9.

6. Poonam, Uprety D, Banerjee B. Ectopic pregnancy - two years review from BPKIHS, Nepal. Kathmandu Univ Med J (KUMJ). 2005;3(4):365-9.

7. Gurung G, Rana A. Diagnostic dilemma in cases of ectopic pregnancy: a five year prospective study at Trivhuwan University Teaching Hospital. Journal of Institute of Medicine. 2006;28(1):30-2.
8. Pradhan P, Thapamagar SB, Maskey S. A profile of ectopic pregnancy at Nepal Medical College teaching hospital. Nepal Med Coll J. 2006 Dec;8(4):238-42.

9. Gurung G, Rana A. Pre-operative hemoglobin level: Correlation with hemoperitoneum in ectopic pregnancy. $\mathrm{N}$ J Obstet Gynaecol. 2007;2(1):39-43.

10. Karki C, Karki A, Yangzom K. Ectopic Pregnancy and its Effect on Future Fertility. South Asian Federation of Obstetrics and Gynecology. 2009;1(1):35-9.

11. Ibrahim NA, Oludara MA, Omodele FO. Surgical and Gynaecological Abdominal Emergencies in Adults: The Experience of Lagos State University Teaching Hospital, Ikeja, Lagos State, Nigeria. Nigerian Hospital Practice. 2010;5(3-4):31-5.

12. Awori MN, Jani G. Surgical implications of abdominal pain in patients presenting to the Kenyatta National Hospital casualty department with abdominal pain. East Afr Med J. 2005;82:307-10.

13. Sardar SAK, Nausheen S, Zahid M, Khalid J. Gynaecological conditions presenting to general surgeons as acute abdomen. Annals. 2009;15(3):146-8.

14. Evsen MS, Soydinc HE. Emergent gynecological operations: A report of 105 cases. J Clin Exp Invest. 2010;1(1):12-5. 